\title{
Agricultura Natural em Angola: a voz dos gestores
}

\author{
Marcelo de Sousa Corrêa' \\ André Faria de Pereira Neto ${ }^{2}$ \\ Carmem Luiza Cabral Marinho ${ }^{3}$
}

\section{Introdução}

Angola é um país com uma grande diversidade climática, demográfica, biológica, social, cultural e étnica. De acordo com o Relatório do Ministério de Urbanismo e Ambiente de Angola (2006), o país possui uma grande extensão geográfica, cobrindo uma superfície de 1.246.700 milhóes $\mathrm{km}^{2}$, com uma população estimada em cerca de 15 milhóes de habitantes. Angola tem duas estações climáticas: uma estação seca, menos quente, chamada de Cacimbo, que se desenvolve no período de maio a setembro, e outra mais quente, caracterizada pelas chuvas, e que compreende os meses de setembro a abril. O país possui uma grande bacia hidrográfica e três áreas agrícolas principais: o norte, o sul e o planalto central. Elas representam as áreas com as principais características climáticas e geográficas do país. Possui recursos

1 Mestre em Saúde Pública pela Escola Nacional de Saúde Pública/Fundação Oswaldo Cruz, Brasil.

2 Doutor em Saúde Coletiva (IMS/UERJ). Pesquisador da Escola Nacional de Saúde Pública (FIOCRUZ/RJ).

3 Doutora em Saúde Pública pela ENSP - Fundação Oswaldo Cruz, FIOCRUZ/RJ, Brasil. 
naturais substanciais, vastos recursos marinhos e fluviais, extensas áreas de floresta, assim como grandes reservas de petróleo e gás natural, minerais valiosos e, particularmente, diamantes. Tem um importante potencial hidroelétrico, com chuvas anuais que excedem $1.000 \mathrm{~mm}$ (Pain, 2007).

Os analistas observam que, apesar da vasta biodiversidade, o espaço geográfico com todo o seu potencial natural foi pouco utilizado. Esse fato está associado em larga medida ao processo de ocupação e exploração dos portugueses no país. Entre os séculos XV e XX, eles não tinham interesse no desenvolvimento agrário da região. A sua presença se fazia presente apenas no litoral. Seu foco estava direcionado à exploração de fontes minerais, aos produtos tropicais e à captura de escravos para alimentar o tráfico negreiro para as Américas. A presença portuguesa em Angola deixou um legado social e econômico muito importante: por um lado, construiu uma estrutura fundiária baseada na grande propriedade exportadora e, por outro, deixou à margem milhares de pessoas que tinham muita dificuldade de sobreviver (Pain, 2007a).

Durante o século XX, Angola foi palco de intensos conflitos sociais que buscavam a independência do país, conquistada apenas em 1975. A partir de então, o Governo de Angola passou a adotar uma série de políticas públicas voltadas para o combate à fome e à pobreza do povo. Essas iniciativas estavam baseadas em campanhas agrícolas de caráter pontual e assistencial que priorizavam a educação, a saúde e a organizaçáo de uma infraestrutura rural. Por essa razão, muitos camponeses abandonaram suas terras e migraram para as cidades, onde passaram a viver em condiçóes extremamente precárias de vida (PINTO, 2008).

Esse cenário pode ser observado no relatório da "Organização das Naçóes Unidas para Agricultura e Alimentação” (FAO), publicado em 2005. Segundo esse documento, $57 \%$ das aldeias e cidades rurais tinham um sistema de latrinas funcionando. Além disso, $80 \%$ da população não tinha acesso a medicamentos essenciais, devido ao seu alto custo, e apenas $10 \%$ tinha acesso a fontes protegidas de água. Esse quadro favoreceu a propagação de doenças como a malária, o sarampo, a tuberculose e a AIDS. Alem disso, a mortalidade infantil e adulta do país atingiu índices muito elevados (PNUD/ONU, 2005).

Outro relatório, publicado dessa vez pela "Organização das Nações Unidas” (PNUD/ONU) em 2005, registrou uma taxa de 260 mortes/ano 
de crianças até os cinco anos de idade (PNUD/ONU, 2005). Esses dados justificam-se pelo fato de $86 \%$ das crianças, durante os seis primeiros meses de vida, não receberem leite materno. Por essa razão, elas têm o dobro de chance de morrer por diarreia ou pneumonia do que aquelas que foram amamentadas. Tal quadro é reiterado no Relatório do Programa Alimentar Mundial das Naçóes Unidas, publicado no mesmo ano. Esse documento indicou que $52 \%$ das crianças com menos de cinco anos de idade do Planalto Central de Angola sofrem de nanismo e podem ficar permanentemente incapazes de levar uma vida inteiramente produtiva. Em síntese, o relatório concluiu que Angola é o segundo pior país do mundo para uma criança nascer, perdendo apenas para Serra Leoa (Pain, 2007).

O relatório do "Programa das Naçóes Unidas para o Desenvolvimento de Angola” (PNUD/ANGOLA), publicado também em 2005, revela que $68 \%$ da população em Angola vivem abaixo da linha da pobreza - 26\% destas na pobreza extrema ou na indigência. Esse quadro se acentua nas zonas rurais, onde $94 \%$ da populaçáo vivem na pobreza extrema, enquanto, nas áreas urbanas, essa situação reduz-se para 57\% das famílias. O documentou registrou ainda que $51 \%$ das pessoas que moram na capital estáo abaixo da linha de pobreza, e que a população de Luanda, na sua maioria, está concentrada em áreas de favela. Tais dados se justificam porque Angola apresentou um dos piores Índices de Desenvolvimento Humano (IDH) do mundo, o que o colocou em 2009 na posição 143 do ranking mundial do IDH num total de 182 .

Diferentes organizaçôes não governamentais têm desenvolvido iniciativas voltadas para atenuar essa situação. Uma delas foi a "Associação para o Desenvolvimento da Agricultura Natural e Cultura Africana” (AFRICARTE), vinculada à Igreja Messiânica Mundial. Essa entidade introduziu, a partir de 1999, em Angola, um programa de hortas caseiras que utiliza o método da Agricultura Natural. Esse método está fundamentado nas ideias de Mokiti Okada (1882/1955), fundador da Igreja Messiânica no Japão.

Segundo Mokiti Okada (MOA, 1983), no ano de 1934, as fazendas encontravam-se em uma situação muito difícil. Os agricultores que alugavam terras alheias tinham muitos gastos, encontrando-se num estado de extrema pobreza. Em 1934, especialmente na regiáo nordeste, houve grandes danos devido a um fenômeno chamado de Friagem, ou seja, a queda brusca de temperatura, com ventos frios. O clima do Japão varia muito de um lugar 
para outro. No norte, os invernos são frios e com neve. A temperatura pode cair até $-40^{\circ} \mathrm{C}$, e os ventos frios vindos da Sibéria e da Mongólia frequentemente causam grandes nevascas. Com isso, muitos agricultores perderam quase toda a colheita e não tinham sequer o que comer.

A propósito das fazendas agrícolas da época, Mokiti Okada pensou seriamente num meio de ajudar os agricultores pobres que atuavam em pequena propriedade no Japão: o método da Agricultura Natural. Este está baseado em uma atividade primária de base familiar, que reduz os custos da produção, pois não utiliza fertilizantes químicos ou de origem animal. Ao conceber esse método, Okada esperava contribuir para a redução da miséria em que viviam os agricultores no Japão no início do século XX. Os documentos oficiais registram que Okada realizou durante muitos anos experimentos em sua propriedade, vivenciando, na prática, o cultivo agrícola sem fertilizantes ou adubos orgânicos de origem animal. Em 1935, fundou a Igreja Messiânica Mundial do Japão. Em julho do mesmo ano, resolveu divulgar os resultados obtidos em suas experiências com o cultivo sem fertilizantes. Com isso, conseguiu aumentar o número de praticantes desse método agrícola no Japão (MOA, 1983).

Durante a Segunda Guerra Mundial, o Japáo passou por momentos de extrema pobreza e fome. Naquele contexto, a prática da Agricultura Natural parece ter obtido bons resultados. Algumas famílias, com terrenos escassos ou com solos pobres, e principalmente aquelas que não tinham nenhuma experiência na prática agrícola e estavam passando por dificuldades financeiras extremas, passaram a adotar esse método. Adotando tal método essas famílias conseguiram o suficiente para se alimentar e não morrer de fome (MOA, 1983). Mas a divulgação efetiva desse método só foi iniciada após a guerra. Em dezembro de 1948, foi publicado o primeiro número da revista "Tijo Tengoku” e, nele, Mokiti Okada, sob o pseudônimo de "Shin-no-Sei", publicou pela primeira vez um artigo sobre o assunto, intitulado "O cultivo sem fertilizantes". Mais tarde, publicou várias revistas que davam enfoque ao novo método e empenhou-se em divulgá-lo, de modo que ele se expandiu gradativamente por todo o país. A partir de outubro de 1950, foi definido o nome do método "Agricultura Natural" - ficando decidido desenvolver essa atividade separadamente das atividades religiosas. Nessa ocasiāo, o fundador compôs vinte e sete poemas com o tema "Maná da Vida". Citamos um pequeno trecho: 
"Chegou a hora de salvar os agricultores, respeitados como grande tesouro desde os tempos antigos."

"Que tolice pesquisar o tão profundo mistério do solo através da tão supérflua ciência!”

Tais poemas tinham como objetivo divulgar suas experiências com a prática da Agricultura Natural por todo o Japão. Em seus artigos, Mokiti Okada realçava que o grande erro da agricultura tradicional teria sido o de não ter considerado a capacidade produtiva do solo, assim como sua capacidade de recuperação natural. Okada salienta que o manejo inadequado do solo pela agricultura tradicional promoveu o uso de adubos orgânicos e agrotóxicos para aumentar a produção e combater as pragas e as doenças das plantas. Segundo ele, a agricultura tradicional tem consequências para a saúde de quem produz e de quem consome os alimentos. Além disso, ela interfere de forma nociva no meio ambiente, sem conseguir resolver o problema da fome e da miséria do mundo. Para Okada, a fertilização do solo implicaria o retorno às suas condiçóes naturais, antes da interferência do homem. Os resíduos de adubos orgânicos ou agrotóxicos não devem ser adotados para que o solo tenha uma produção satisfatória de alimentos. Este deve estar exposto ao sol, sendo suficientemente abastecido com água e matéria orgânica vegetal. Segundo Okada, a Agricultura Natural pode ser praticada por qualquer pessoa em qualquer parte do mundo. Ela tem a capacidade de permitir a subsistência e de gerar renda para as famílias de camponeses. Por essa razão, sua adoção pode ter consequências econômicas, sociais e ambientais. A Agricultura Natural tornou-se um dos pilares da expansão da Igreja Messiânica Mundial no Japão e em outras partes do mundo, inclusive em Angola, através da AFRICARTE.

Este artigo busca resgatar o processo histórico de organização e atuação da AFRICARTE entre 2000 e 2010, através do depoimento de quatro dos seus principais gestores, que também tinham vínculo com a Igreja Messiânica Mundial. Este trabalho visa ainda a analisar os laços existentes entre a associação e essa Igreja. Ele discute a utilização da Agricultura Natural como estratégia de expansão das atividades da Igreja Messiânica Mundial em Angola. O pequeno número de documentos escritos disponíveis sobre essa experiência fez com que a utilização da História Oral passasse a ser 
decisiva na investigação que se transformou neste artigo. Este trabalho não visou a trazer respostas definitivas sobre o problema abordado, mas iniciar, estimular e enriquecer o debate sobre a Agricultura Natural e as alternativas de combate à fome.

\section{Metodologia}

Este trabalho fez uso do método de História Oral para análise dos depoimentos dos quatro principais gestores da AFRICARTE que vivenciaram todo o processo de implantação e desenvolvimento do método de Agricultura Natural em Angola. A decisão pelo método inicialmente se justifica pelo pequeno número de documentos oficiais e de material bibliográfico acadêmico sobre o desenvolvimento do trabalho e o caráter específico dos objetivos da pesquisa. Além disso, a escolha desse método teve como objetivo o resgate da história de vida dos entrevistados. Com isso, permitiu a recuperação daquilo que não pode ser encontrado em documentos de outra natureza, como acontecimentos que foram pouco esclarecidos ou nunca evocados, experiências pessoais e impressóes particulares dos entrevistados. Observou-se que a grande vantagem da História Oral reside no fato de ela privilegiar a recuperação do vivido conforme concebido por quem viveu (Alberti, 2005).

Através da análise de documentos e dos depoimentos dos gestores da AFRICARTE, buscou-se montar um repertório. O repertório foi construído com o objetivo de relacionar e integrar documentos do arquivo institucional, do arquivo pessoal e do acervo de depoimentos orais. De acordo com André F. de Pereira Neto (1997), um repertório, tecnicamente falando, "é um instrumento de pesquisa que descreve e referencia documentos pertencentes a um ou mais fundos ou acervos relevantes para um determinado tema" (Pereira Neto, 1997, p.02).

Para tanto, foram coletados documentos institucionais da AFRICARTE e da Igreja Messiânica Mundial de Angola, assim como livros e revistas escritos por Mokiti Okada. Essa análise de documentos teve como objetivo verificar a existência de uma relação entre a fundamentação técnica da Agricultura Natural e a base teológica da Igreja Messiânica Mundial. Foram analisados também arquivos pessoais e experiências vivenciadas 
pelos entrevistados visando a identificar que tipo de relação existe entre os gestores da AFRICARTE e a Igreja Messiânica Mundial. Outro objetivo foi o de identificar uma possível influência da fé messiânica na tomada da decisão dos entrevistados de aderir ao método de Agricultura Natural como estratégia de expansão da Igreja Messiânica Mundial em Angola. Além disso, foi construido um acervo de História Oral com o depoimento de quatro gestores que tiveram atuação destacada no processo de institucionalizaçáo da AFRICARTE e que vivenciaram todo o processo de implantação e desenvolvimento do método de Agricultura Natural em Angola. Os entrevistados foram selecionados devido à relevância e à particularidade de suas informaçóes. $\mathrm{O}$ roteiro que orientou as entrevistas procurou inicialmente identificar como se desenvolveu o processo de implantação da Agricultura Natural em Angola, construindo um arquivo oral que fornecesse subsídios para uma história institucional. Além disso, o roteiro preocupava-se com a reconstituição das trajetórias profissionais dos gestores, necessárias para identificar a existência de vinculação entre estes, a relação desses gestores com a prática da Agricultura Natural e com a Igreja Messiânica Mundial. No roteiro estava presente ainda a preocupaçáo com a avaliaçáo que os entrevistados fariam sobre os avanços e entraves enfrentados durante a implantação e o desenvolvimento do método de Agricultura Natural através de hortas caseiras em Angola. As entrevistas foram realizadas em 2010, na sede da Fundação Mokiti Okada, no Rio de Janeiro. Os depoimentos e os documentos que compóem o repertório deste trabalho foram analisados após a aplicação da técnica de saturação.

Esse método é operacionalmente definido como a suspensão de inclusão de novos participantes ou informaçóes em um trabalho acadêmico, quando os dados obtidos passam a apresentar, na avaliação do pesquisador, certa redundância ou repetição, não sendo considerado relevante persistir na coleta de dados. O ponto de saturação é alcançado quando as novas informaçóes fornecidas pelos participantes da pesquisa pouco acrescentam ao material já obtido e não contribuem significativamente para o aperfeiçoamento da reflexão teórica ou empírica desenvolvida (Fontanella et al., 2008).

O acervo de História Oral, com os depoimentos dos quatro gestores, encontra-se gravado em mídia audiovisual (DVD) e digitalizado. Além disso, as quase 08 horas de gravação foram transcritas e sofreram conferência de fidelidade. Todo o material está disponível para consulta na Biblioteca da 
Escola Nacional de Saúde Pública da Fundação Oswaldo Cruz, no estado do Rio de Janeiro, e na Biblioteca da Faculdade Messiânica da Fundação Mokiti Okada, em São Paulo.

Para atender aos objetivos do trabalho, foram escolhidos os seguintes gestores da AFRICARTE:

\begin{tabular}{|l|l|l|}
\hline Nome & Nascimento & Função \\
\hline Francisco Jésus Fernandes & $1946-2010$ & Presidente/AFRICARTE \\
\hline Cláudio Cristino L. Pinheiro & 1973 & Vice-Presidente/AFRICARTE \\
\hline Marques Zambu Bambi & 1956 & Coordenador Técnico \\
\hline Hiroshi Ota & 1967 & Coordenador de Pesquisa \\
\hline
\end{tabular}

Apresentaremos a seguir o perfil dos depoentes. A apresentação visa a justificar a escolha destes para o presente trabalho.

\section{O perfil dos depoentes}

Francisco Jésus Fernandes chegou em Angola em 1991. Até então, era responsável pelas atividades pastorais da Igreja Messiânica na regiáo Norte e Nordeste do Brasil. Quando chegou à África, Angola estava passando por uma Guerra Civil, e o país assolado pela fome e a miséria. Duas questóes nos parecem pertinentes a seu respeito: Como ele chegou à Igreja Messiânica? Por que razão foi escolhido para desempenhar esse papel?

Fernandes é brasileiro, nascido em Juiz de Fora, no dia 28 de agosto de 1946. Aos dezesseis anos de idade, tornou-se jogador de futebol no Rio de Janeiro, tendo atuado como atleta profissional nos times do Botafogo, Flamengo e na seleção Brasileira. No início da década de 1970, começou a frequentar a Igreja Messiânica Mundial do Brasil (IMMB) no Rio de Janeiro. $\mathrm{O}$ ingresso na IMMB permitiu que ele começasse a conhecer os princípios da Agricultura Natural.

Francisco Jésus Fernandes disse que:

Inicialmente eu entrei para a Igreja Messiânica para receber benefícios e poder jogar futebol. Quer dizer, inicialmente as minhas ambiçóes eram muito egoístas. Mas, a partir do instante em que fui vendo os resultados, 
lendo os ensinamentos, conhecendo o projeto de Mokiti Okada para o mundo, eu me apaixonei por esse projeto e resolvi dedicar a minha vida, doar a minha vida para ajudar as outras pessoas. /.../ essa transformaçáo ocorreu em mim gradualmente /.../ (Depoimento de Francisco Fernandes).

Quando chegou à Angola, Fernandes não possuía qualquer experiência na prática agrícola e também não tinha formação nem experiência como gestor de projetos. Estes não parecem ter sido os motivos que o levaram até aquele país africano. $\mathrm{O}$ que parece ter sido decisivo foi o lugar de prestígio e poder que ele passou progressivamente a ocupar durante os anos 1980 na Igreja Messiânica no Brasil. Assim que abandonou a carreira de jogador de futebol, passou a assumir cada vez mais responsabilidades com esse movimento religioso. Entre 1976 e 1986, exerceu a função de sacerdote da Igreja Messiânica no Rio de Janeiro. Em seguida, passou a assumir a mesma função na Bahia. Logo depois, foi nomeado responsável pela expansão da Igreja Messiânica em toda a regiáo Nordeste do Brasil. A confiança que tinha da cúpula da Igreja Messiânica brasileira e mundial foi determinante, a nosso ver, em sua nomeação. Sua ascensão na hierarquia da Igreja Messiânica não se encerrou em Angola. Pelo contrário. A experiência de gestão adquirida através das atividades pastorais da Igreja Messiânica e na coordenação do projeto de Agricultura Natural em Angola o credenciaram a ocupar novas funções na instituição. Ao falecer, no dia 14 de abril de 2010, Francisco Jésus Fernandes ocupava os cargos de vice-presidente da Igreja Messiânica Mundial do Brasil e presidente da Igreja Messiânica Mundial de Angola. Durante o período em que esteve na Bahia, foi professor de Cláudio Cristino Leal Pinheiro. A relaçáo de confiança e identidade que se estabeleceu entre eles foi responsável pela ida de Cláudio para Angola em 1997.

Cláudio Pinheiro é brasileiro. Ele nasceu em 1973, na Bahia. Diferindo de Francisco Fernandes, a Agricultura Natural foi para ele a porta de entrada para a Igreja Messiânica. Buscando um método alternativo de cura para a asma de que seu pai sofria, conheceu em 1977 a Agricultura Natural preconizada por Mokiti Okada. Utilizando suas técnicas em uma horta caseira, observou que a saúde de seu pai melhorava consideravelmente, chegando a ficar muitos meses sem crise respiratória. Pinheiro, ao perceber a influência da prática da Agricultura Natural e de uma alimentação saudável na vida de seu pai, decidiu se aprofundar nos ensinamentos de Mokiti Okada. Anos 
depois, entrou para o seminário de formação sacerdotal da Igreja Messiânica. No seminário, conheceu Francisco Jésus Fernandes e, com sua orientação, decidiu se preparar para se dedicar integralmente à expansão da fé messiânica e da Agricultura Natural no continente africano. Para isso, Cláudio, durante o Seminário de Formaçáo Sacerdotal, fez um breve estágio no Centro de Pesquisa da Fundação Mokiti Okada no Brasil. Na oportunidade, pôde visitar produtores rurais e investigar mais sobre os resultados da prática da Agricultura Natural. Dessa experiência, Cláudio Pinheiro realça um momento especial que marcou sua trajetória de vida:

/.../ Até o dia daquela visita, mesmo tendo essa base familiar, aquilo estava adormecido em mim. Mas, no dia que nós visitamos esse produtor, ele falando como era a vida dele... Não era membro da nossa Igreja, mas ele contando que ele, antes de conhecer a agricultura natural, o sofrimento dele e da esposa utilizando os agrotóxicos, eram muitas doenças, a pobreza náo saía da vida deles. E depois que eles tiveram contato com o nosso método, eles começaram a praticar, começaram a recuperar aquele solo, começaram a ver os resultados. /.../ naquele dia, a agricultura natural entrou em meu coração e pensei: puxa vida! /.../ a partir dá eu comecei a estudar mais sobre agricultura natural. Fui para o Japão, e lá procurei conversar com os pioneiros desse método agrícola, conversando com eles, busquei aprender com suas experiências. (Depoimento de Cláudio Pinheiro).

A história da família Bambi é parte de um processo de colonização, escravidáo e luta pela independência de Angola. Marques Zambo Bambi nasceu em Angola no dia 16 de dezembro de 1956. Ele é filho de pais analfabetos e agricultores, integrantes da etnia Ambacongo, de uma regiáo no norte de Angola, da província do Kwanza Norte. Em 1979, Marques foi estudar em Cuba; inicialmente, dedicou-se à formação de técnico em química e depois fez sua graduaçáo na área de engenharia agrônoma. Em 1987, Bambi retornou a Angola. Na oportunidade, uma gastrite crônica e úlceras estomacais que havia adquirido durante seus estudos em Cuba se agravaram. No seu entender, esse quadro foi consequência da alimentação que consumira, cultivada com o uso de adubos e agrotóxicos. Além disso, seu organismo não respondia aos medicamentos. Na oportunidade, conheceu a Agricultura Natural. Como agrônomo, náo conseguia aceitar seus fundamentos, pois havia aprendido, durante sua formação, a importância 
de se aplicar adubos e agrotóxicos no cultivo agrícola. Com relação a essa desconfiança, Marques diz:

Certo dia ouvi a palestra do Reverendo Francisco. Quando ele chegou na parte onde explica o método da agricultura natural, eu disse: está totalmente ao contrário daquilo que eu estudei na universidade! Entáo ele começou a explicar sobre agricultura natural, e durante a palestra eu levantava a mão. Disse: olha, o Senhor falou isto, isto, isto. /.../ e eu dizia: não! Não concordo! Não concordo porque eu aprendi assim, assim, assim. O Senhor está a falar assim ao contrário! Aí disse, está bom. Ele continuou a falar. E eu levantei a mão. Eu disse, não! Ele disse-me assim, espera, no final depois vamos falar (Depoimento de Marques Bambi).

Depois de assistir a algumas palestras sobre o tema, apesar de reticente, decidiu introduzir em sua casa o cultivo em hortas caseiras, baseando-se nos princípios técnicos da Agricultura Natural. Aos poucos, segundo ele, não conseguia entender por que seu estado de saúde melhorava. Por essa razão, resolveu aprofundar seus estudos nos ensinamentos de Mokiti Okada, principalmente naqueles que se referiam à Agricultura Natural. Seu envolvimento com a Agricultura Natural teve, portanto, um componente epistemológico não desprezível. Acostumado a seguir os princípios da tradicional agricultura, Bambi se surpreendia com o que conhecia e observava.

Com o apoio da Igreja Messiânica Mundial, Bambi realizou, em 1994, um estágio no Polo de Agricultura Natural de Cruz das Almas, na Bahia, e depois no Polo de Atibaia, ambos tendo como mantenedora de seus recursos a Igreja Messiânica. Em seguida, foi até a sede do "Centro de Pesquisa da Fundação Mokiti Okada” (CPMO), em Ipeúna - São Paulo. No CPMO, recebeu orientação da equipe técnica formada por doutores em Agronomia, especialistas em Agricultura Natural e Agroecologia, em que se destaca a PhD Ana Primavesi, pioneira da Agroecologia no Brasil. Nessa época, Bambi conheceu Hiroshi Ota - Coordenador de Pesquisa do CPMO. Segundo o engenheiro Marques Z. Bambi, foi a partir das experiências adquiridas no estágio e com o consequente encontro com Hiroshi Ota que se começou a estudar a possibilidade de uma cooperação técnica do "Centro de Pesquisa da Fundação Mokiti Okada” em Angola.

Ao retornar, começou a implantar o método através de hortas caseiras e realça como foi o processo de aceitação dos agricultores: 
Olha muitos agricultores /.../ tinham suas pequenas propriedades, muitos deles já não usavam adubos químicos. Então, quando introduzimos a agricultura natural, que não usa nenhum adubo químico, eles abraçaram facilmente a ideia e gostaram da experiência. Para eles não era algo estranho não (Depoimento de Marques Bambi).

Cláudio Pinheiro e Marques Z. Bambi foram, portanto, atraídos para a Igreja Messiânica através da Agricultura Natural. Pode-se verificar, portanto que, apesar de não existir uma fundamentação teológica na Agricultura Natural, inicialmente sua expansão esteve associada a interesses políticos de expansão dessa instituição religiosa em território africano. Por se tornar um homem de confiança para Francisco Fernandes, Cláudio Pinheiro foi nomeado para seguir para Angola. Atualmente, com o falecimento de Francisco Jésus Fernandes, Cláudio Pinheiro foi nomeado presidente da Igreja Messiânica Mundial de Angola.

A história de Hiroshi Ota é bem diferente da dos outros atores que foram selecionados para a entrevista que serviu de base para o desenvolvimento deste artigo. Ota nasceu no Japáo, em 1967. Seus pais foram agricultores da província de Gifu, região central do Japão. Durante a Segunda Guerra Mundial, conheceram e aprenderam pessoalmente com Mokiti Okada os fundamentos da Agricultura Natural. Durante muitos anos, Hiroshi Ota aprendeu os ensinamentos sobre Agricultura Natural com Katsuiti Watanabe, discípulo direto de Okada, tendo difundido essa prática agrícola em diferentes situaçóes e regióes do Japão. Com a morte de Katsuiti Watanabe, em Fevereiro de 1991, Ota foi convidado pelos dirigentes da Igreja Messiânica Mundial do Japáo para difundir no Brasil sua experiência adquirida com a prática da Agricultura Natural. Hiroshi Ota foi Coordenador de Pesquisa do Centro de Pesquisa da Fundação Mokiti Okada no Brasil. O fato de ter sido aprendiz de Watanabe conferiu a Ota um conhecimento e uma imagem compartilhada por poucos membros da Igreja Messiânica Mundial.

Segundo Ota, a instituição, no Brasil, de um Centro de Pesquisa em 1996, foi uma estratégia adotada pela Fundação Mokiti Okada com recursos financeiros da Igreja Messiânica Mundial do Brasil com o intuito de obter o reconhecimento acadêmico de sua pratica agrícola. Outra estratégia foi expandir a Agricultura Natural para o continente africano, marcado historicamente pela fome. Ota parece ter sido uma peça central no processo de 
implantação da Agricultura Natural em Angola. Quando chegou ao Brasil, enfrentou muitas dificuldades com relação ao idioma, além de sofrer com o preconceito das pessoas pelo fato de ser japonês, mas, aos poucos, foi conquistando adeptos e simpatizantes do método de Agricultura Natural. Com dificuldades de se expressar corretamente em português, Ota, em seu depoimento, confirmou a estratégia da Igreja Messiânica Mundial em relação à organização desse centro de pesquisa, ao dizer:

Para gerar o conhecimento, foi criado um centro de fomento que se transformou no Centro de Pesquisa Mokiti Okada para desenvolver as atividades de pesquisa. Em 1996, este Centro de Pesquisa foi inaugurado com o objetivo de ampliar os estudos e pesquisa sobre a agricultura natural e meio ambiente. Os resultados deveriam ser repassados para o produtor rural. /.../ mas precisava de dinheiro. A Igreja Messiânica tornou-se a fonte mantenedora do Centro de Pesquisa (Depoimento de Hiroshi Ota).

O encontro de Hiroshi Ota com Marques Zambo Bambi deu-se com a decisão da Direção da IMMA de enviar o engenheiro Bambi para estagiar sob a supervisão de Ota no Centro de Pesquisa no Brasil em 1994. Esse encontro despertou o desejo de se estabelecer uma experiência com a prática da Agricultura Natural em Angola como uma alternativa para a reduçáo da fome e da miséria naquele país que sofria com as consequências de um estado pós-guerra.

\section{A implantação da Agricultura Natural em Angola}

Como resultado da aplicação do método de História Oral, verificou-se nos depoimentos que o engenheiro agrônomo angolano Marques Bambi desempenhou papel central na introdução da Agricultura Natural em Angola, sobretudo em Luanda. De acordo com os quatro entrevistados, foi Bambi que começou a divulgar esse método através da implantação de hortas caseiras. No início, o trabalho teve como público-alvo principal os membros e simpatizantes da Igreja Messiânica Mundial de Angola (IMMA), devido à disposiçáo de cada família de colocar em prática os ensinamentos de seu fundador, Mokiti Okada. Segundo os próprios gestores do projeto, essa disposição pode ter 
sido motivada pela crença que cada pessoa que adotou esse método tinha na proposta de Mokiti Okada. Segundo os depoentes, não houve imposição por parte da Igreja Messiânica para que seus seguidores experimentassem esse método no quintal de suas casas. Na verdade, essas famílias passavam por dificuldades semelhantes às outras, que não eram membros da IMMA ou simpatizantes dos ensinamentos de Okada. As famílias que foram pioneiras no projeto de desenvolvimento da Agricultura Natural acreditavam que nada tinham a perder. Elas achavam que já tinham perdido quase tudo na guerra e foram convencidas por Bambi de que esse método permitiria o acesso a um alimento saudável. Apesar da vinculação explícita de interesses entre a introdução da Agricultura Natural e a expansão da Igreja Messiânica em Angola, os gestores deixaram claro nas entrevistas que o método apresentado poderia ser adotado por qualquer pessoa, independente de credo, sexo ou raça.

A trama de interesses recíprocos ficou ainda mais evidente durante a introdução da Agricultura Natural em Angola. Os quatro entrevistados deixaram claro que a Agricultura Natural começou a ser adotada pelos fiéis da Igreja Messiânica e que contou com seu financiamento. Eles afirmaram que, para começar o trabalho, foi necessário utilizar essas pessoas e os recursos providos pela Igreja Messiânica, já que não dispunham de dinheiro para desenvolver o trabalho sem apoio. Em termos retóricos, os quatro entrevistados acreditavam que, com os resultados obtidos com as hortas caseiras, poderiam influenciar outras pessoas e criar uma associação independente e sustentável. Ficou claro na voz dos depoentes que o interesse despertado pela Agricultura Natural junto aos cidadãos em condiçóes de miséria os aproximaria da Igreja Messiânica. Além disso, ficou evidente que Okada serviria de elo entre os dois pontos, na medida em que integra a base filosófica da Igreja Messiânica e da Agricultura Natural. Parte dessas ideias pode ser observada no depoimento de Bambi:

Olha, todo mundo tem necessidade de comer. Todo mundo tem necessidade de aprender, e então /.../ quando há facilidade, ou alguém apresenta interesse de querer aprender, nós não fechamos as portas. Ainda mais quando se trata de uma filosofia de cultivo da terra. /.../ Neste caso nós abrimos as portas para todo mundo! Não importa se é branco, se é preto, se é mestiço, se é amarelo, se é índio. Nós abrimos as portas para todo mundo. E não importa também se é da nossa religião ou não. /.../ Nós somos abrangentes (Depoimento de Marques Bambi). 
Não pode ser desconsiderado, entretanto, o objetivo da Igreja Messiânica de criar condiçóes para o desenvolvimento da Agricultura Natural em Angola. Não deve ser esquecido que os resultados dessa atividade agrícola permitiram o acesso da população angolana a um alimento mais saudável, assim como contribuiu para sua subsistência e a geração de renda para cerca de oito mil famílias (Pinheiro, 2009). Observamos nos depoimentos um propósito de benevolência e filantropia na implantação desse projeto que não pode ser negligenciado.

Com resultados positivos, foi crescente a procura pelo modelo de hortas caseiras da Agricultura Natural. Com isso, aumentou o número de famílias que adotaram o método agrícola. Contudo, devido à grande demanda de pessoas, o acompanhamento individual dessas famílias torna-se inviável e desgastante. A necessidade de institucionalização dessa experiência tornou-se ainda mais premente. Nesse momento decisivo, entrou em cena Francisco J. Fernandes que, naquele contexto, foi capaz de demonstrar sua capacidade de articulação política com governos, partidos e a Igreja. Ele apresentou ao Governo Angolano os resultados positivos das experiências iniciais obtidas com a implantação do "Programa de Hortas Caseiras". Com isso, o governo do país cedeu para a Igreja Messiânica um terreno de 13 hectares, na comuna do Bom Jesus, no Bengo, a cerca de duas horas da capital, Luanda. Apesar de ser distante da capital, a concessão dessa área foi fundamental para a criação, em 2000, do "Polo de Agricultura Natural do Bom Jesus". Com a aquisiçáo do terreno, cresceu a necessidade de se institucionalizar o Programa e de expandi-lo para a sociedade de uma forma mais sistemática. Para isso, foi fundada a "Associação para o Desenvolvimento da Agricultura Natural e Cultura Africana” (AFRICARTE). De acordo com os gestores, a AFRICARTE é uma instituição sem fins lucrativos, de utilidade pública, reconhecida pelo Governo de Angola e que tem a Igreja Messiânica Mundial de Angola como mantenedora e provedora de recursos.

\section{A vinculação com a Igreja Messiânica}

Ouvindo e analisando os depoimentos dos quatro entrevistados podemos construir uma sequência de fatos e acontecimentos que convergiram 
para a implantação da Agricultura Natural em Angola. Os dois atores parecem ter tido uma participação essencial no projeto: Francisco Jésus Fernandes e Hiroshi Ota. O primeiro ocupou-se das estratégias políticas da Igreja Messiânica, o segundo aprofundou-se nas bases técnicas desse método agrícola. Um ocupa lugar público e o outro frequenta os laboratórios e cursos de formação. Como as frentes de ação são diferentes e simultâneas, Francisco Fernandes encontrou em Cláudio Pinheiro a lealdade inerente a um discípulo. Ota fundamenta tecnicamente o discurso político dos demais. $\mathrm{Na}$ execução do projeto, atraindo famílias e formando voluntários, encontra-se o engenheiro Marques Zambo Bambi, único angolano envolvido com o projeto. Por essa razão, ele se torna a frente pública dessa política. Através da análise desses acontecimentos, é possível caracterizar uma relação entre a Agricultura Natural e a Igreja Messiânica. Esse fato torna-se mais evidente na medida em que os quatro atores principais do projeto mantêm uma relaçáo cada vez mais estreita com a Igreja Messiânica Mundial do Brasil e de Angola. Todos os quatro gestores são sacerdotes outorgados pela Igreja Messiânica, que é idealizadora e provedora do projeto de Agricultura Natural.

Esse apoio da Igreja Messiânica ao projeto fica claro no depoimento de Francisco J. Fernandes, quando afirma que:

À medida que a Igreja foi crescendo, ela foi fazendo os investimentos necessários. Então, hoje nós chegamos numa condição de poder investir. /.../ Então, este ano, nós terminamos a parte de construção, quer dizer, de infraestrutura, como a compra de motores e de material agrícola, toda a parte de implementos agrícolas, para que a gente pudesse tocar a obra. Agora, depois dos implementos agrícolas, nós estamos com um investimento de trinta mil dólares/mês. Tudo foi doação da Igreja Messiânica para a AFRICARTE (Depoimento de Francisco Fernandes).

Outra questão seria a existência de alguma vinculação teológica da Igreja Messiânica com a prática da Agricultura Natural. A análise dos depoimentos indica que não. Ao recorrer às obras de Okada intituladas Agricultura Natural, Arte e Sociedade e $O$ homem no cotidiano, ambas extraídas da coletânea de seus ensinamentos, em sua 5a edição (2007), pode-se encontrar um caminho para entender essa pergunta. Nas obras citadas, fica claro que o altruísmo é um dos fundamentos que norteia a prática messiânica defendida por Mokiti Okada. 
Segundo os depoentes, a difusão da Agricultura Natural pode ser vista como mais uma iniciativa visando ao amor ao próximo, exercida com desprendimento e abnegação. Para o altruísta, o interesse e o bem-estar da outra pessoa traduzem a finalidade da vida. Mokiti Okada fundou a Igreja Messiânica em 01 de Janeiro de 1935, no Japão. Ele não tinha a intenção de criar uma religiáo. Seu desejo era criar um movimento que pudesse expandir uma filosofia baseada no espiritualismo e no altruísmo. Se existe esse elo filosófico, cabe enfatizar que a prática da Agricultura Natural serviu em determinados momentos como um instrumento de atração para a Igreja Messiânica. Esse foi o caso de Marques Bambi e de Cláudio Pinheiro, que vivenciaram o sucesso terapêutico da Agricultura Natural e acabaram desvendando suas origens e fundamentos, conhecendo as ideias de Okada, e então passaram a frequentar a Igreja Messiânica. Hoje, os quatro depoentes são sacerdotes dessa instituição.

\section{Avanços e entraves}

Através do discurso dos atores entrevistados, foram identificadas diversas situaçóes que dificultaram o avanço do projeto de desenvolvimento da Agricultura Natural em Angola. A maior dificuldade deriva do cenário que eles encontraram quando começaram a desenvolver esse projeto. Um contexto de fome e miséria, um legado de séculos de colonialismo português somado aos resultados de longos anos de conflito pela independência entre grupos rivais nativos. Eles encontraram um país sem a mínima infraestrutura nas áreas rurais e urbanas. De acordo com os gestores entrevistados, o maior de todos os limitantes ao desenvolvimento do projeto foi a falta de água em muitos lugares. Onde existia água, esta era encontrada imprópria para o consumo humano. As famílias não tinham água para consumo, banho e muito menos para irrigar suas hortas caseiras. Angola não tinha saneamento básico e seu sistema de saúde era precário e deficiente. Além disso, faltava energia elétrica e segurança para a população. A região rural não era um lugar seguro. Guerrilheiros saqueavam casas e atacavam as famílias. As áreas rurais foram minadas durante a guerra e muitos trabalhadores encontravam-se mutilados. Somava-se a esses fatores a concentraçáo populacional, sobretudo na capital 
Luanda, devido ao fluxo migratório dos camponeses para as cidades. Um quadro que, nos últimos anos, não se modificou substancialmente.

Esse contexto pode ser observado no depoimento de Cláudio Pinheiro, quando diz que:

A guerra obrigou as pessoas a migrarem para a capital, o que causou um grande inchaço populacional na capital Luanda. A tática de guerrilha também espalhou muitas minas terrestres. Então, até hoje é um problema que ainda está sendo resolvido. Graças a Deus o governo está desminando o país. O país teve uma época que tinha mais minas do que população. Tinha cerca de doze milhóes de minas e cerca de onze milhões de habitantes. Algo assim. Isso está sendo resolvido. É um processo lento e caro. Mas está sendo resolvido e as pessoas aos poucos estáo a voltar para o interior. Voltar para as suas terras de origem. (Depoimento de Cláudio Pinheiro).

Como a AFRICARTE ficava distante da capital, o acesso dos interessados dependia de transporte urbano. Na região em torno da capital, existia e continua existindo um precário sistema de transporte. De acordo com os depoentes, esse problema dificultava o processo de capacitação e a manutenção das atividades. Além disso, o acompanhamento das famílias que adotaram o modelo da Agricultura Natural e estavam praticando o método através de suas hortas caseiras ficava mais difícil.

Nesse sentido, Cláudio Pinheiro afirma que:

A dificuldade maior é na área de infraestrutura no país, que é algo que graças a Deus o nosso governo está a construir. Porque foram quatro décadas de guerra. Então são sete anos de paz. Está a avançar, mas ainda existe essa dificuldade de infraestrutura, de acesso à água e luz. As estradas estão sendo feitas. A água está sendo levada para os locais. A questão da infraestrutura está sendo resolvida, graças a Deus. Está sendo resolvida a olhos vistos (Depoimento de Cláudio Pinheiro).

Outro entrave foi a falta de elemento humano capacitado na área agrícola. O projeto de introduçáo da Agricultura Natural começou com apenas cinco pessoas, sendo um engenheiro agrônomo, um técnico agrícola e três voluntários. Segundo os depoentes, atualmente a equipe é formada por dezoito pessoas, sendo dois engenheiros agrônomos, três técnicos e treze 
funcionários sem capacitação específica. Com isso, podemos verificar que, em dez anos de projeto, quase não houve investimento em recursos humanos e nem na aquisição de material e equipamento.

Segundo os depoentes, as campanhas agrícolas implantadas pelo Governo de Angola teriam contribuído mais com o desenvolvimento agrícola do país se náo tivessem adotado o modelo convencional de produção. Esse modelo utilizava insumos agrícolas como adubos e agrotóxicos, com apoio de verba internacional com o objetivo de combater a fome no país. Esse modelo convencional foi aplicado a uma população na sua maioria analfabeta, sem acesso a técnicos capacitados para orientar o uso adequado desses insumos. Os trabalhadores rurais náo tinham a percepção do risco ao manejar a terra utilizando esses produtos. Eles desconheciam o risco do contato direto, sem proteção e sem orientação decorrente do uso de adubos e agrotóxicos. Esses fatos dificultaram ainda mais a introdução da Agricultura Natural.

\section{Perspectivas}

Como parte final das entrevistas, os gestores deixaram claro em seu discurso a necessidade da AFRICARTE de se tornar uma instituição autossuficiente e com recursos para investir em recursos humanos e equipamentos. Segundo os depoentes, o projeto, ao melhorar sua capacidade de gestão, poderá comercializar os produtos cultivados nas hortas caseiras. A comercializaçáo desses produtos poderá gerar renda para os agricultores, assim como proporcionar investimentos na AFRICARTE.

Confirmando as perspectivas para a expansão do trabalho da AFRICARTE, Francisco Fernandes afirmou que:

Nós vamos construir em Bom Jesus a Escola de Agricultura Natural. É nosso plano. Nós já estamos elaborando um anteprojeto, para ser apresentado à direção da Igreja no Japão. Em seguida nós vamos realmente construir essa escola agrícola, para cerca de trezentos alunos/.../ com cursos de agricultura natural. Vamos preparar bem o elemento humano em dois anos, criando alojamentos, mantendo essas pessoas integradas com a natureza e com a prática da agricultura natural. É preciso qualificar principalmente o jovem, 
para que possam ser inseridos como técnicos agrícolas no mercado de trabalho em todo continente africano. Hoje nós podemos já pensar nisso, porque hoje alcançamos certa condição financeira. E com os resultados do nosso trabalho na expansão da agricultura natural, esperam-se não só as ONGs /.../ mas o próprio governo e empresas privadas vão querer participar financeiramente para que a AFRICARTE possa ampliar esse modelo para toda a África. (Depoimento de Francisco Fernandes).

De acordo com os gestores, existe o desejo de estreitar a cooperaçáo técnica entre a AFRICARTE e o Centro de Pesquisa da Fundação Mokiti Okada no Brasil. Com esse apoio, eles planejam construir uma Escola de Técnicas Agrícolas Naturais em Angola. Em setembro de 2011 foi iniciada a obra da escola agrícola.

\section{Considerações finais}

Após a análise do depoimento dos gestores, consideramos que as entrevistas foram de grande relevância para a recuperação da história da experiência de hortas caseiras com aplicação do método de Agricultura Natural em Angola. Com a recuperação dessa trajetória, torna-se possível avaliar melhor as dificuldades encontradas e as estratégias de ação, assim como desenvolver e criar novas perspectivas e modelos de gestão para a implantação da Agricultura Natural em países do continente africano.

Com isso, o trabalho náo teve como objetivo trazer respostas, mas iniciar e enriquecer o debate sobre a Agricultura Natural, assim como estimular novos estudos acadêmicos sobre o tema.

\section{Referências}

ANGOLA. Plano Nacional de Desenvolvimento Humano - PNUD. Relatório de Desenvolvimento Humano - Angola, 2005.

ALBERTI, Verena. Manual de História Oral. 3. Ed. Rio de Janeiro: Editora FGV, 2005. p. $29-41$. 
BAMBI, Marques Zambu. Depoimento Oral. Engenheiro Agrônomo. Coordenador Técnico da AFRICARTE. Dez. 2009.

EHLERS, Eduardo. Agricultura Sustentável: perspectivas de um novo paradigma. Ed. Guaíba: Agropecuária, 1999. V. 2. 157p.

FERNANDES, Francisco Jésus. Depoimento Oral. Vice-Presidente da Igreja Messiânica Mundial do Brasil. Presidente da Igreja Messiânica Mundial de Angola. Dez. 2009.

FONTANELLA, Bruno José Barcellos; RICAS, Janete; TURATO, Egberto Ribeiro. Amostragem por saturaçâo em pesquisas qualitativas em saúde: contribuições teóricas. Cad. Saúde Pública, Rio de Janeiro, v. 24, n. 1, jan. 2008.

OKADA, Mokiti. Alicerce do Paraíso. Editora Fundação Mokiti Okada. Brasil. 5. Ed. v.4, junho, 2007.

MOA. Fundação Mokiti Okada. Luz do Oriente. Biografia de Mokiti Okada. Editora Fundação Mokiti Okada. Brasil.1ª ed. v. 2, junho, 1983.

OTA, HIROSHI. Depoimento Oral. Coordenador de Pesquisa. Centro de Pesquisa da Fundação Mokiti Okada. Brasil. Dez. 2009.

PEREIRA NETO, André de F. 1997 - A história oral da criação do Conselho de Medicina: notas sobre uma experiência. In: VON SIMSON, Olga R. de Moraes (Org.). Os desafios contemporâneos da história oral. Campinas: Área de Publicaçôes CMU/Unicamp.

PAIN, Rodrigo de Souza. Desafios da Participação Social em um País de Conflito Agudo: estudo a partir da ONG Angolana - Ação para Desenvolvimento Rural e Ambiente (ADRA). Tese de doutorado- UFRRJ, 2007.

PAIN, Rodrigo de Souza. A questão da terra em Angola: velhos problemas, velhas soluçóes. Cadernos do CEOM (UNOESC), v. 27, p. 71/27-88, 2007.

PAIN, Rodrigo de Souza. A sociedade civil angolana e a (difícil) busca pela democracia. Revista Múltipla (UPIS), v. 16, p. 47-69, 2007a.

PINHEIRO, Claudio Cristino Leal. Depoimento Oral. Vice-Presidente da IMMA. Gestor da AFRICARTE. Dez. 2009.

PINTO, João Nuno da Silva. A construção da politica de segurança alimentar e nutricional em Angola. Dissertação de Mestrado. CPDA/UFRRJ, RJ, 2008. p.11-125.

Resumo: $\mathrm{O}$ presente artigo busca investigar a trajetória histórica e as experiências adquiridas pela "Associação para o Desenvolvimento da Agricultura Natural e Cultura Africana" (AFRICARTE) com a adoção do método de Agricultura Natural em Angola, no período de 2000 a 2010. Os critérios utilizados para a escolha da instituição e dos entrevistados foi prin- 
cipalmente a possibilidade de se investigar possíveis interesses comuns entre a AFRICARTE e a Igreja Messiânica Mundial, que é mantenedora dos projetos dessa associação. A pesquisa teve como hipótese a existência de vínculos entre a teologia da Igreja Messiânica Mundial e a fundamentação técnica da Agricultura Natural. Com isso, visando a atender aos objetivos traçados pela pesquisa, foi escolhido o método de História Oral como instrumento de investigação. Para isso, foram escolhidos quatro dos principais gestores da AFRICARTE que tiveram um vínculo com a Igreja Messiânica Mundial. A escolha dos depoentes sustenta-se a partir do momento em que se discute a utilizaçẫo da Agricultura Natural como estratégia de expansão das atividades da Igreja Messiânica Mundial em Angola. Com isso, o trabalho não teve como objetivo trazer respostas, mas iniciar e enriquecer o debate sobre a Agricultura Natural, assim como estimular novos estudos sobre o tema.

Palavras-chave: agricultura, cultivos agrícolas, desenvolvimento sustentável, religião, Angola.

\title{
Nature Farming In Angola: the voice of managers
}

\begin{abstract}
The present study search to investigate the historical trajectory and the experience gained by the "Association for the development of agriculture, natural and African culture" (AFRICARTE), with the practice of Nature Farming method in Angola during 2000 to 2010. The criterion for choice of institution and of interviewees was mainly the possibility of investigating possible common interests between AFRICARTE and World Messianic Church, which is the main sponsor of AFRICARTE projects. With that, was chosen the oral history method as research instrument. For this were chosen only the four main AFRICARTE managers due to its link with the World Messianic Church. The choice if sustains when discussing the use of Nature Farming as expansion strategy of the activities of the World Messianic Church in Angola. With this work was to bring responses, but start and enrich the debate on agriculture as well as stimulate new studies on the topic.
\end{abstract}

Keywords: agriculture, agricultural crops, sustainable development, religion, Angola.

Recebido em: 14/03/2012

Aprovado em: 27/04/2012 